\title{
PUBOVAGINAL SLING IN THE TREATMENT OF STRESS URINARY INCONTINENCE FOR URETHRAL HYPERMOBILITY AND INTRINSIC SPHINCTERIC DEFICIENCY
}

\author{
AGNALDO L. SILVA-FILHO, SÉRGIO A. TRIGINELLI, MAURÍCIO B. NOVIELLO, \\ ADMÁRIO S. SANTOS-FILHO, CLEIDISMAR R. PIRES, J. RENAN CUNHA-MELO \\ Department of Gynecology and Obstetrics, Department of Surgery, and Section of Urology, School of \\ Medicine, Federal University of Minas Gerais, Belo Horizonte, Minas Gerais, Brazil
}

\begin{abstract}
Purpose: This study was undertaken to evaluate the use of pubovaginal sling for the treatment of female stress urinary incontinence in patients with intrinsic sphincteric deficiency and patients with urethral hypermobility.

Materials and Methods: Sixty-two patients aging 22 to 73 years-old $($ mean $=49.6)$ with a median parity of 4.1 (range 0 - 14) who underwent pubovaginal autologous fascial sling procedures for stress urinary incontinence from August/1999 to August/2002 were prospectively analyzed. Objective pre and postoperative urodynamic evaluation was performed in all cases. The patients were divided into 2 groups: thirty-nine patients $(62.9 \%)$ with urethral hypermobility (Valsalva leak point pressure equal or superior to $60 \mathrm{~cm}$ of $\mathrm{H}_{2} \mathrm{O}$ ) and twenty-three patients $(37.1 \%)$ with intrinsic sphincteric insufficiency (Valsalva leak point pressure below $60 \mathrm{~cm}$ of $\mathrm{H}_{2} \mathrm{O}$ ).

Results: The average follow-up period was 24.8 months, ranging from 3 to 38 months. Three patients $(4.8 \%)$ had detrusor overactivity before the operation, and 36 patients $(58.1 \%)$ had voiding dysfunction before surgery. The postoperative objective cure rate was $88.7 \%$ for stress urinary incontinence. The study also showed that $32.2 \%$ of the patients had voiding dysfunction and $11.3 \%$ had detrusor overactivity. The mean hospital stay was 3.1 days (range 2 - 4). No difference in the above parameters was noticed between patients with intrinsic sphincteric deficiency and those with urethral hypermobility.

Conclusion: Construction of a pubovaginal sling is an effective technique for the relief of severe stress urinary incontinence, for both patients with urethral hipermobility and with intrinsic sphincteric deficiency, having a cure rate of $88.7 \%$. The high frequency of postoperative voiding urgency was not related to the detrusor overactivity as evaluated by urodynamic studies.
\end{abstract}

Key words: urinary incontinence, stress; urodynamics; surgical technique; pubovaginal sling Int Braz J Urol. 2003; 29: 540-544

\section{INTRODUCTION}

Since the beginning of the $20^{\text {th }}$ century, using a series of materials, sling procedure has been described for the treatment of female urinary incontinence (1). The use of a strip of rectus fascia beneath the bladder neck by a vaginal incision and anchored superiorly in the abdominal wall was proposed by Aldrige in 1942 (2).

Sling attachment to the abdominal aponeurosis would provide its movement with the abdominal wall during the increase of the intraabdominal pressure. During cough or sneeze, the outwards movement of the abdominal wall would 
draw the sling upwards with consequent increase of the urethral pressure (2). More recent studies have shown that the endopelvic fascia has an important function in giving support to the urethra during stress $(3,4)$. Thus, the suburethral sling, instead of raising and actively compressing urethra during the effort, would act in a similar way as the endopelvic fascia, supporting the urethra and making a passive resistance of urethra possible during the increase of intraabdominal pressure (1).

Traditionally, slings have been indicated for the treatment of the recurrent stress incontinence, especially in patients who presented a scarred and fixed urethra leading to a defective urethral sphincter function and lower maximum urethral closure pressure (1). The indication of sling as the first choice for all stress incontinence cases leads to about $90 \%$ of cure (5). These high rates of success of the suburethral sling for the treatment of stress incontinence are associated with the new pathophysiological concepts of the stress incontinence. The development of less invasive techniques with synthetic material has been responsible for the renovated interest in the use of sling for the treatment of the female urinary incontinence.

The aim of this study was to evaluate the pubovaginal sling technique with rectus fascia for the treatment of stress incontinence, comparing the results in patients with urethral hypermobility to those with intrinsic sphincteric deficiency.

\section{MATERIALS AND METHODS}

Sixty-two patients ranging in age from 22 to 73 year-old (mean $=49.6 \pm 12.2$ ) were prospectively studied, with diagnosis of stress incontinence and submitted to surgical treatment using the pubovaginal sling with rectus fascia between the period of August/ 1999 and August/2002.

All patients provided a detailed history, which included an incontinence impact questionnaire to assess the impact in quality of life before treatment, physical examination, urine culture, and urinalysis. The objective quantification of the severity of incontinence was done by the mean stress leaking point pressure in the urodynamic study. All patients were assessed preoperatively by a multichannel urodynamic study that included flowmetry, postvoid residual volume measurement by urethral catheter, and a cystometrogram. Valsalva leak point pressure was assessed by visual examination of the urethral meatus at the time of a Valsalva maneuver with the bladder filled to the volume of first desire to void (average $220 \mathrm{~mL}$ ). An urodynamic study was performed, postoperatively, during the period of 3 to 6 months in all cases.

\section{Surgical Technique}

1) Patient placed in the dorsal lithotomy position under peridural anesthesia; 2) Transversal suprapubic incision for withdrawal of the rectus fascia strip with dimension of $10 \times 2 \mathrm{~cm}$; 3) Closure of the aponeurosis with 1-Vicryl ${ }^{\circledR}$ thread; 4) Preparation of the strip tying both edges with 0-Prolene ${ }^{\circledR}$, leaving the wire with long extremities; 5) Use of a Foley catheter to empty the bladder; 6) Submucosal saline injection on the anterior vaginal wall; 7) Longitudinal incision of the anterior vaginal wall $2 \mathrm{~cm}$ distant from the urethral orifice; 8) Dissection of the vaginal mucosa until identification of the retropubic space; 9) Positioning of the strip of rectus fascia with aid of the Raz's needle around the middle urethra; 10) Maintenance of the strip without tension through approach of wires in the mid plan; 11) Closure of both vaginal mucosa and skin.

The procedures associated with sling were colpoperineoplasty in 41 patients $(66.1 \%)$, vaginal hysterectomy in 3 patients $(4.8 \%)$ and tubal ligation in 3 patients $(4.8 \%)$. The mean follow-up of the patients was $24.8 \pm 7.1$ months, ranging from 3 to 38 months.

To evaluate significant differences between the groups, the $\chi 2$ test and Fischer's exact test were used. The level of significance was set at $p<0.05$.

\section{RESULTS}

The mean parity of the patients was $4.1 \pm 3.1$ childbirths (range 0 - 14 childbirths) and 11 patients (17.8\%) presented previous cesarean sections; 13 
(21\%) cases had already been previously submitted to surgery for correction of urinary incontinence. The operative procedure was Burch procedure in 8 (12.9\%) patients and anterior repair in $5(8.1 \%)$ patients.

The preoperative urodynamic studies showed genuine stress incontinence in 59 patients $(95.2 \%)$ and mixed incontinence in 3 patients $(4.8 \%)$. These 3 patients had already been submitted to medical treatment. Voiding urgency was present in 36 patients $(58.1 \%)$ prior to surgery. The mean stress leaking point pressure in the preoperative urodynamic study was $73.2 \pm 34.6 \mathrm{~cm}$ of $\mathrm{H}_{2} \mathrm{O}\left(11-150 \mathrm{~cm}\right.$ of $\left.\mathrm{H}_{2} \mathrm{O}\right)$.

Patients were divided into two groups: 1) Group 1: patients with diagnosis of urethral hypermobility with a Valsalva leak point pressure equal or superior to $60 \mathrm{~cm}$ of $\left.\mathrm{H}_{2} \mathrm{O}(\mathrm{n}=39 ; 62.9 \%), 2\right)$ Group 2: patients with diagnosis of intrinsic sphincteric deficiency presenting a Valsalva leak point pressure below $60 \mathrm{~cm}$ of $\mathrm{H}_{2} \mathrm{O}(\mathrm{n}=23 ; 37.1 \%)$.

No significant differences in relation to age, parity or presence of pelvic floor defects, as cystocele, rectocele, enterocele or perineal rupture, were noticed in the two groups of patients. The only difference between the patients with urethral hypermobility and those with intrinsic sphincteric deficiency was the stress leaking-point pressure, 91.7 and $41.7 \mathrm{~cm} \mathrm{H}_{2} \mathrm{O}$ respectively ( $\mathrm{p}<0.001)$ (Table-1).

Ten patients (16.5\%) presented postoperative urinary retention, 3 (4.8\%) of them needed suprapubic cystostomy. Twenty patients $(32.2 \%)$ had shown micturitional urgency, 12 of them (19.3\%) presented persistent micturitional urgency and 8 patients (12.9\%) "de novo" micturitional urgency. The postoperative urodynamic study has shown no inhibited contractions of the detrusor in only 7 patients $(11.3 \%)$.

Seven patients $(11.3 \%)$ persisted with stress urinary incontinence, which was confirmed by the postoperative urodynamic study. There was no statistical difference between the mean stress leaking point pressure in the preoperative and postoperative urodynamic study of these patients $(63 \pm 10.8 \mathrm{~cm}$ versus $56 \pm 14.3 \mathrm{~cm}$ of $\left.\mathrm{H}_{2} \mathrm{O}, \mathrm{p}=0.354\right)$.

No statistical difference was observed between patients with urethral hypermobility and those with intrinsic sphincteric deficiency concerning urinary retention, need of postoperative cystostomy, "de novo" and persistent micturitional urgency and postoperative subjective stress urinary incontinence nor in the urodynamic study findings of detrusor overactivity or stress incontinence (Table-2). The average hospitalization time was of $3.1 \pm 0.9$ days for the two groups of patients. As it can be noticed, there was no difference between any of the analyzed parameters in the two groups of patients.

\section{DISCUSSION}

The comparison of the results after sling procedures is difficult since the studies evaluate populations of different patients, especially those with recurrent stress urinary incontinence and the series of comparative studies are so small. The objective cure rate was $88.7 \%$ whereas the subjective cure rate

Table 1 - Clinical and physiopathological characteristics in the patients with urethral hypermobility and intrinsic sphincteric insufficiency.

\begin{tabular}{lccc}
\hline & $\begin{array}{c}\text { Urethral } \\
\text { Hypermobility } \\
(\mathbf{n = 3 9 )}\end{array}$ & $\begin{array}{c}\text { Intrinsic Sphincteric } \\
\text { Deficiency } \\
(\mathbf{n = 2 3 )}\end{array}$ & $\mathbf{p}$ \\
\hline Mean age & $48.7 \pm 9.8$ & $55.6 \pm 10.5$ & 0.068 \\
Mean parity & $4.18 \pm 3,0$ & $4.23 \pm 2.7$ & 0.962 \\
Pelvic floor defects & $30(76.9 \%)$ & $13(56.5 \%)$ & 0.272 \\
Previous voiding urgency & $26(66.7 \%)$ & $10(43.5 \%)$ & 0.285 \\
Previous incontinence procedure & $6(15.4 \%)$ & $7(30.4 \%)$ & 0.21 \\
Valsalva leak point pressure $\left(\mathrm{cm} \mathrm{H}_{2} \mathrm{O}\right)$ & $91.7 \pm 26.9$ & $41.7 \pm 20.5$ & $<0.001$ \\
\hline
\end{tabular}


Table 2 - Postoperative complications in patients with urethral hypermobility and intrinsic sphincteric deficiency.

\begin{tabular}{lccc}
\hline Complication & $\begin{array}{c}\text { Group of Patients } \\
\text { Untrinsic Sphincteric } \\
\text { Deficiency } \\
(\mathbf{n}=\mathbf{2 3})\end{array}$ & $\mathbf{p}$ \\
\hline Urinary retention & $(\mathbf{n = 3 9 )}$ & $3(13 \%)$ & 0.660 \\
Cystostomy & $7(17.9 \%)$ & 0 & 0.444 \\
Persistent micturitional urgency (subjective) & $3(7.7 \%)$ & $3(13 \%)$ & 0.631 \\
"De novo" micturitional urgency (subjective) & $9(23.1 \%)$ & $4(17.4 \%)$ & 0.578 \\
Detrusor overactivity (urodynamic study) & $4(10.2 \%)$ & $4(17.4 \%)$ & 0.554 \\
Stress urinary incontinence (subjective) & $3(7.7 \%)$ & $4(17.4 \%)$ & 0.19 \\
Stress urinary incontinence (urodynamic study) & $3(7.7 \%)$ & $4(17.4 \%)$ & 0.19 \\
\hline
\end{tabular}

was $84.1 \%$, comparable to the literature data that showed objective cure rates from 61 to $100 \%$ and subjective cure rates from 73 to $93 \%$ (1).

Some authors had shown better rates of objective and subjective cure, besides fewer incidences of complications, with the surgery of Burch (6). A review comparing the treatment of the stress urinary incontinence by sling to other techniques such as abdominal and laparoscopic colposuspension, suspension with needle and anterior repair showed no significant differences (7).

There is little data regarding the long-term results. The recurrence of symptoms, when present, usually occurs in the first six months, and is usually secondary to the degeneration of the strip or loss of the sutures. After this period the success of the surgery is known to last for many years $(8,9)$. The mean follow-up of our patients was $24.8 \pm 7.1$ months ( 3 38 months). The results of sling in the treatment of urethral deficiency and urethral hypermobility in a long follow-up, with a mean time of 42 months ( 0.5 134 months) have shown a rate of objective cure of $97 \%$ and voiding dysfunction of $41 \%$. Improvement of the quality of life occurred in $88 \%$ and improvement of the urinary continence occurred in $84 \%$ of the patients. When asked if they would submit to this procedure again, $82 \%$ of patients answered yes (10).

There is a current concept that suburethral sling is more obstructive than the other techniques for treatment of stress urinary incontinence. In this study, 10 patients $(16.5 \%)$ presented postoperative urinary retention, and $3(4.8 \%)$ of them had a suprapubic cistostomy done. The incidence of urinary retention varies from 2.2 to $16 \%$, and from 1.5 to $7.8 \%$ of the patients that need autocatheterism (11). There is a tendency to gradually reduce the tension of the strip in the sling, diminishing the obstructive character of the procedure with consequent improvement of the voiding difficulties and the postoperative instability of the detrusor $(1,12)$. There are proposals of methods that assist in the adjustment of the strip, as the use of a swab in urethra and evaluation of its angulation (13).

The incidence of postoperative voiding urgency varies from 3 to $30 \%$, being the detrusor overactivity evidenced in $7 \%$ of the patients (14). Twenty patients $(32.2 \%)$ had presented micturitional urgency, 8 of them (12.9\%) had "de novo" micturitional urgency. The urodynamic study evidenced no inhibited contractions of the detrusor in only 7 patients $(11.3 \%)$. This may indicate that the micturitional urgency is not caused by detrusor overactivity in the majority of the cases.

An important factor in the comparison of results of the sling surgery among different surgeons is the variability of the technique. Questionnaires answered by surgeons have shown discordance rates of $42 \%$ in the type of material used, $19 \%$ in the dimensions of the strip and $19 \%$ in the method used for traction. The only factor with less variability was 
the point of attachment of the sling (15). This can explain the discrepancies observed in the results reported by different groups and the different technical options for the treatment of the stress urinary incontinence.

\section{CONCLUSION}

We concluded that the pubovaginal sling is an effective technique for the treatment of female stress urinary incontinence, for patients both with urethral hypermobility and with intrinsic sphincteric deficiency, with an $88.7 \%$ of cure rate. The high frequency of postoperative voiding urgency is not related to the detrusor overactivity evaluated by urodynamic studies.

\section{REFERENCES}

1. Bidmead J, Cardozo L: Sling techniques in the treatment of genuine stress incontinence. BJOG. 2000; 107: 147-56.

2. Aldridge AH: Transplantation of fascia for the relief of urinary incontinence. Am J Obstet Gynecol. 1942; 44: 398-411.

3. DeLancey JOL: Structural support of the urethra as it relates to stress urinary incontinence: the hammock hypothesis. Am J Obstet Gynecol. 1994; 170: 171323.

4. Zacharin RF: Abdomino-perineal suspension in the management of recurrent stress incontinence of urine - a 15 years experience. Obstet Gynecol. 1989; 96: 213-20.

5. Chaikin D, Rosenthal J, Blaivas G: Pubovaginal fascial sling for all types of stress urinary incontinence: long term analysis. J Urol. 1998; 160: 1312-6.
6. Maher CF, Dwyer PL, Carey MP, Moran PA: Colposuspension or sling for low urethral pressure stress incontinence? Int Urogynecol J Pelvic Floor Dysfunct. 1999; 10: 384-9.

7. Bezerra CA, Bruschini H: Suburethral sling operations for urinary incontinence in women. Cochrane library, Issue 1, 2002.

8. Jarvis GJ: Stress Incontinence. In: Mundy AR, Stephenson TP, Wein AJ (eds.). Urodynamics: Principles, Practice and Application. New York, Chuchill Livingstone. $2^{\text {nd }}$ ed, 1994, pp. 299-326.

9. Morgan JE, Heritz DM, Stewart FE, Connolly JC, Farrow GA: The polypropylene pubovaginal sling for treatment of recurrent stress urinary incontinence. J Urol. 1995; 154: 1013-5.

10. Richter HE, Varner RE, Sanders E, Holley RL, Northen A, Cliver SP: Effects of pubovaginal sling procedure on patients with urethral hypermobility and intrinsic sphincteric deficiency: would they do it again? Am J Obstet Gynecol. 2001; 184: 14-9.

11. Ghonheim G, Shaaban A: Suburethral slings for the treatment of stress urinary incontinence. Int Urogynecol J Pelvic Floor Dysfunct. 1994; 5: 228-39.

12. Appell R: Primary slings for everyone with genuine stress incontinence? The argument for. Int Urogynecol J Pelvic Floor Dysfunct. 1998; 9: 249-51.

13. Nguyen A, Mahoney S, Minor L, Ghoniem G: A simple objective method of adjusting sling tension. J Urol. 1999; 162:1674-6.

14. Leach G, Dmochowski R, Appell R, Blaivas JG, Hadley HR, Luber KM, et al.: Female stress urinary incontinence clinical guidelines panel summary report on surgical management of female stress urinary incontinence. J Urol. 1997; 158: 875-80.

15. Walter AJ, Buller JL, Davis G: Variability of reported techniques for performance of the pubovaginal sling procedure. Int Urogynecol J Pelvic Floor Dysfunct. 2002; 13: 160-4.
Received: June 26, 2003

Accepted after revision: October 24, 2003

\section{Correspondence address:}

Dr. Agnaldo Lopes da Silva Filho

Avenida Pasteur, 89 / 1310

Belo Horizonte, MG, 30150 290, Brazil

E-mail: agsilvaf@terra.com.br 